\title{
COVID19 - A Daredevil or A Blessing In Disguise
}

\author{
Inayat Thaver, Fouzia Naeem Effendi, Fareeha Shahid
}

How to cite this Article:

Thaver I, Effendi FN, Shahid F. COVID19 - A Daredevil or A Blessing In Disguise. J Bahria Uni Med Dental Coll. 2020;11(1):01-03. DOI: https://doi.org/10.51985/XGRF9897

$\overline{\text { This is an Open Access article distributed under the terms of the Creative Commons Attriution Non Commercial Liciense (http:// creativecommons/org/licences/by-nc/4.0) }}$ which permits unrestricted non commercial use, distribution and reproduction in any medium, provided the original work is properly cited.

COVID19 starting as an epidemic last year (2019) from

Wuhan, China got converted into a pandemic within months with its devastating ravages throughout the world. The pandemic and its spread with its severity affected both poor and rich countries equally, which had a larger population. The measures taken by China, though, were initially challenged and even termed against the 'human rights' for the complete lockdown but soon were adopted by many countries. Suddenly, the need for ICUs and ventilators in them jumped throughout the world ${ }^{1}$, the value and demand for doctors, especially the clinicians managing the emergencies was brought to the limelight ; all types of borders within and between the countries were closed for any movements and above all the social media became active with all the myths, misinformation and warnings about COVID19. The WHO, amidst all this chaos, took up the steering role for addressing and managing the pandemic. Various SoPs (standard Operating Procedures) were prepared, which by and large focused on a) social distancing b) wearing masks, and c) cleaning or sanitizing the hands regularly. ${ }^{2}$ Suddenly, the soaps, sanitizers, and masks became expensive to the extent that at many places, they were not available. All the intuitions or areas where there was a potential of the larger gathering were closed, including offices, educational intuitions, markets, malls, and even parks and playgrounds were closed. Initially, it meant getting locked at home or getting necessary essential items, including food from someone else, or taking the risk of going out and getting these essential items. The various scientists related to Pathology/virology, public health experts, and health policy and planners also joined the bandwagon to address this pandemic. All the businesses, both local and international, plunged, and countries showed a downward trend. ${ }^{3}$ Each

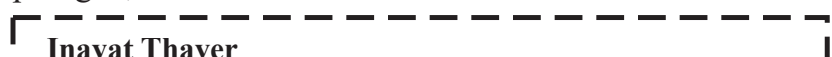

Inayat Thaver

I Professor and HoD, Department of Community Health

Sciences,

Bahria University Medical and Dental College, Karachi

I Email: inayat.bumde@bahria.edu.pk

Fouzia Naeem Effendi

I Senior Lecturer, Department of Community Health Sciences,

I Bahria University Medical and Dental College, Karachi

I Fareeha Shahid

Assistant Professor

Department of Community Health Sciences,

I Bahria University Medical and Dental College, Karachi

Received: 01-Oct-2020

I Accepted: 07-Dec-2020 day, the number game of in-country and other countries globally was flashed on TV and social media, giving the counts of those infected and those admitted in the ICU and the ones who died. Soon, we came to know some of the potential risk factors and various theories about the natural history of the disease and its multiple causations. Various 'trials' and/or experiments were conducted claiming a drug or an approach's success. Initially, a phase of denial and conspiracy prevailed among many, including the developed countries' leaders. Lack of adequate emergency facilities prompted the riots, protests, and criticism by political opponents. Domestic violence, closure essential, and many other emergencies and surgical services, laying off of workers in various offices and institutions, were noticed, including increased sufferings faced by the daily wage workers, vulnerable population, and the poor . ${ }^{4}$

Against all these backdrops, there was a silver lining, seizing the opportunities and demonstration of philanthropy to address all these devastations and human sufferings. The frontline doctor- young, adult, and experts went out of the way to play their role by working long hours and risking their own lives. Various educational intuitions and offices and businesses started converting into digital approaches, and suddenly, the demand for connectivity increased everywhere. ${ }^{5}$ Online businesses were launched, especially by many young startups and entrepreneurs. The use of new and existing software and programmes were being recommended, followed by their training and then active use, especially for teaching purposes. Various volunteers mobilized themselves for helping the poor, unemployed, and those who were quarantined but did not have any support at home or in hospitals. ${ }^{6}$ The clinicians, especially the Infectious disease specialists, Pulmonologists, ICU and emergency specialists, pathologists/virologists, and other clinical disciplines, jumped in to manage and identify the treatment of the COVID19 dynamic but also for vaccination. The Public Health experts, especially the Epidemiologists and Infectious diseases experts, commenced their modeling about diseases' behaviour and how it can be prevented and then ultimately controlled. ${ }^{7}$ Various laboratories and big commercial pharmacological and bio-medical companies started producing more cost-effective and quick detection tests. The WHO, including many other international bodies, made standard guidelines for managing the COVID19 and other related issues such as reproductive health, routine 
immunization, and reporting and monitoring system. State of the art reports and data management for recording cases followed by monitoring the cases were developed, including various local apps, quick fever detection systems, and mass screening. Thus, it seemed that there is war throughout the world, and all countries are global, though individually are participating in defeating that unforeseen enemy. All the countries organized various approaches some standard (as recommended by WHO or had been tried out successfully by others) or innovated their indigenous techniques. Thus, besides the terminology of "lockdown, others were coined, such as "smart lockdown" or "mini-lockdown," etc. The strange behavior of the spread of the virus in various countries has puzzled many scientists, especially in Asian countries, including that of Pakistan. ${ }^{8}$ This is in stark contrast to our immediate neighbor India where the situation is still out of control. The success observed in Pakistan may be due to the policies and programmes, or having some inherent immunity or striking at the right moment. New family reunions have been a very welcoming change for various societies, getting to disintegration. This only happened due to the lockdown forced by COVID19. People are getting more mindful of each other; the role of counsellors, psychologists, and psychiatrists could not be undermined who had proactively played their role due to lockdown consequences, including many mental health problems. Suddenly, we saw the surge of many 'YouTube channels' and so many potential stars who are active in sharing their knowledge, experiences, and reflections on various topics. ${ }^{9}$ In that context, the role of religious scholars should also be mentioned who had actively participated in spreading relevant health education messages, especially in the Muslim world. The most famous buzz word among these "new norms" (as they say) ${ }^{10}$ is the WFH, i.e., working from home. The WFH appears to be highly practiced and has been successful in many circumstances; however, some barriers or potential issues have also been noted. For the first time, we should consider whether we need to physically go to the office or other places instead of doing it whole sitting from home. The WFH benefitted the crumbling economy and has improved the overall situation mainly because of decreased smoke from vehicles and being on the roads for quite a time while going to the offices. The participation in home chores besides by the women only at home has been another welcoming change. There had been reports that the men and children have started participating in some household chores; of course, there are exceptions to another extreme of domestic violence. ${ }^{11}$

Most governments have suddenly realized that they need to invest more and put a bigger pie of the budget for health. This has also been supported by various development partners and international non-government organizations. The decline in the cases and morbidity and mortality in many countries has been reported for a few months, but they say that war is not over. There are potential dangers of a resurgence, especially with winter; some countries have reported the emergence of the virus in various places and gone back to lockdown or, to be more precise, smart or selective lockdown; this is now true for Pakistan, also. Based on the previous downwards trend of COVID19 cases, the Pakistan government has decided to open educational institutions; this has though followed after allowing the multiple businesses, especially the markets and malls, with the recommendations to observe SoPs. ${ }^{12}$ However, in countries where there is a continuous downward trend, the people (or even government) are going into complacency and not fully observing the SoPs. The fears of resurgences of COVID19 is getting true, especially in Western countries where the winter has already commenced. In Pakistan, are also getting the resurgence, and it has been reported that the nation again has positive cases what it used to have back in July. We have yet to wait and see how things will turn out. However, we are passing through history after the last pandemic of plague, and we still need to know much more about the disease. However, various claims have been made for remarkable progress in producing and testing out the vaccine. But some scientists do tell us that the vaccine may not be the answer. The bigger question is, do we have to follow the 'new norm,' or we can go back to the era of BC, i.e., "before Corona." Amid so many deaths and miseries, humanity is still alive. Thus, we have developed resilience, forbearance and have demonstrated so many untapped potentials to work around and keep the life and businesses moving on. Imagine a situation of BC (Before Corona). In the ' $\mathrm{BC}$ ' period, we may not have advanced so much in utilizing digital technology and the health advances including the innovations to address a pandemic. The blessing in disguise has been to capture opportunities for getting nearer to family members (especially to the old ones) and the Almighty Allah and divine power Who controls and takes care of us.

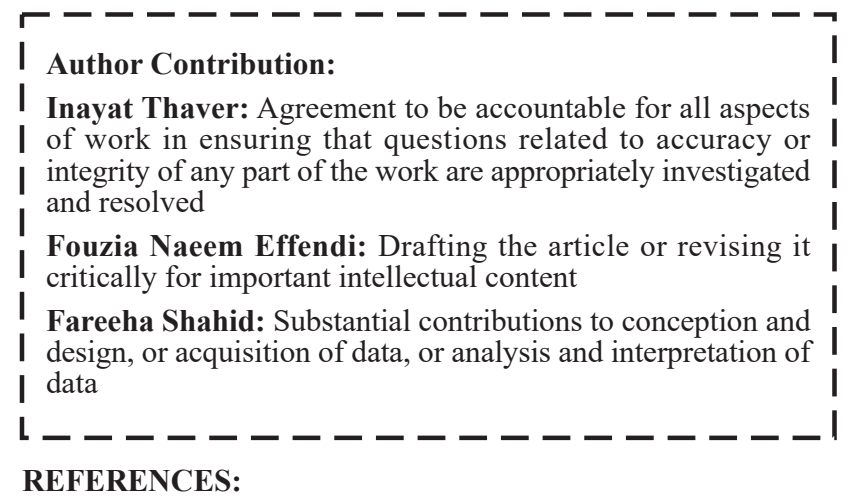

1. Ranney ML, Griffeth V, Jha AK. Critical supply shortages the need for ventilators and personal protective equipment during the Covid-19 pandemic. New England Journal of Medicine. 2020;382(18):e41. 
2. WHO Water, sanitation, hygiene, and waste management for the COVID-19 virus Interim guidance 23 April 2020. https://www.who.int/water sanitation health/newsevents/wash-and-covid19/en/

3. Sahni H, Sharma H. Role of social media during the COVID19 pandemic: Beneficial, destructive, or reconstructive?. International Journal of Academic Medicine. 2020;6(2):70.

4. International Growth Centre. Responding to the impacts of COVID-19 on informal workers in South Asia. Available from https://www.theigc.org/blog/responding-to-the-impactsof-covid-19-on-informal-workers-in-south-asia/ [Accessed 21 September 2020]

5. Pandey N, Pal A. Impact of Digital Surge during Covid-19 Pandemic: A Viewpoint on Research and Practice. International Journal of Information Management. 2020:102171.

6. OECD. Youth and COVID-19: Response, recovery and resilience. Available from: https://www.oecd.org /coronavirus /policy-responses/youth-and-covid-19-response-recoveryand-resilience-c40e61c6/ [Accessed 21 September 2020]

7. Barati M, Bashirian S, Jenabi E, Khazaei S, KarimiShahanjarini A, Zareian S, Rezapur-Shahkolai F, Moeini B. Factors associated with preventive behaviours of COVID-19 among hospital staff in Iran in 2020: an application of the Protection Motivation Theory. Journal of Hospital Infection. 2020;105(3):430-3.
8. The New York Times. As new corona virus spread, China's old habits delayed Fight. Available from: https://www.nytimes. com/2020/02/01/world/asia/china-coronavirus.html [Accessed 21 September 2020]

9. Rogers JP, Chesney E, Oliver D, Pollak TA, McGuire P, FusarPoli P, Zandi MS, Lewis G, David AS. Psychiatric and neuropsychiatric presentations associated with severe coronavirus infections: a systematic review and meta-analysis with comparison to the COVID-19 pandemic. The Lancet Psychiatry. 2020 May 18.

10. Ashraf H, Faraz A, Raihan M, Kalra S. Fighting pandemics: Inspiration from Islam. JPMA. The Journal of the Pakistan Medical Association. 2020;70(5):S152-6.

11. P S, Shahid M. Work from home during covid 19: Employees perception and experiences. Global Journal For Research Analysis. 2020 May 18.

12. International Monetary Fund. The IMF and COVID-19. Available from: https://www.imf.org/en/Topics/imf-andcovid19 [Accessed 21 September 2020] 